\section{Does hospital noise disturb patients?}

Noise is measured in decibels on a logarithmic scale expressing a ratio between a particular sound pressure to a reference level $(0 \mathrm{~dB})$ :

$$
\text { measured air pressure }(\mathbf{P a})
$$

$$
1 \mathrm{~dB}=20 \times \log _{10} \frac{}{20 \mu \mathrm{Pa} \text { (smallest air pressure perceived by } 50 \% \text { adults) }}
$$

Subjectively, an increase of $10 \mathrm{~dB}$ makes a sound twice as loud. Filters reduce the response to low frequency noise, and the resultant "weighted" scale is expressed in $\mathrm{dB}(\mathrm{A})$ units. A whisper is therefore recorded at about 20 $\mathrm{dB}(\mathrm{A})$, light traffic at $45 \mathrm{~dB}(\mathrm{~A})$, and a telephone at $60 \mathrm{~dB}(\mathrm{~A})$. Noise levels recommended for hospital wards in the United States are less than $45 \mathrm{~dB}(\mathrm{~A})$ during the day and $35 \mathrm{~dB}(\mathrm{~A})$ at night.' We measured noise levels in several wards overnight.

\section{Methods and results}

Using a graphic recorder (CEL-160) we measured the background noise leve and the number of minutes during which there was a noise registering $>50 \mathrm{~dB}(\mathrm{~A})$ from 2230 to 0630 . Consecutive recordings were also made with a noise average meter (CEL-144), which indicated the average noise over the eight hours on a digital display. Noise levels were measured once in each of six general medical wards and four times in both the acute admitting and psychiatric wards. Statistical analysis of the graphic recordings was by analysis of variance.

We assessed the sleep patterns and attitudes to hospital noise of patients in the six bedded bay closest to the nursing station by questionnaire on the morning after the overnight recording. The attitudes of nursing staff to noise, and suggestions on methods of reducing noise, were sought by questionnaire at the end of the study.

In the general medical wards a noise registering $>50 \mathrm{~dB}(\mathrm{~A})$ occurred in 113 387 minutes out of the total of 480 minutes with a mean (SEM) of $212(40)$ minutes. In the acute and psychiatric wards the ranges were 193-251 and 11-26 minutes and the means 217 (14) and 20 (9) minutes respectively (figure). Thus there was significantly less noise $(p<0.01)$ in the psychiatric than the general and acute medical wards; the general and acute medical wards did not differ significantly from each other.

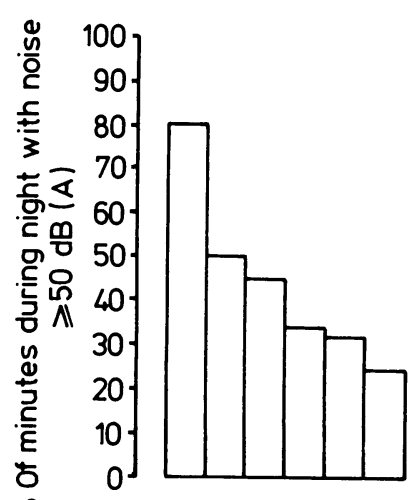

General medical

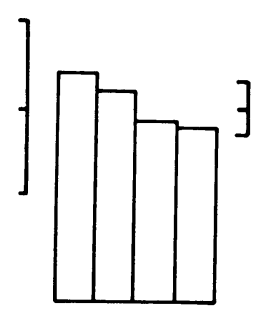

Acute admission

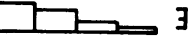

Psychiatry
Proportion of minutes from 1030 to 0630 in which a noise $\geqslant 50 \mathrm{~dB}(\mathrm{~A})$ was recorded with graphic recorder (recordings were made once in each of six general medical wards and on four occasions in one acute admission ward and in one psychiatric ward). Means (SEM) are also shown.

The average noise levels in the psychiatric, general, medical, and acute admitting wards were 49,68 , and $66 \mathrm{~dB}(\mathrm{~A})$ respectively. The increase from 49 to $66 \mathrm{~dB}(\mathrm{~A})$ represents a fourfold increase in perceived noise. Average noise levels from 0700 to 2300 in the general and acute medical wards were almost identical $(67 v 68 \mathrm{~dB}(\mathrm{~A}))$ and were similar to the overnight recordings.

Of 91 patients interviewed, 39 claimed that their sleep was unaltered in hospital compared with at home, 28 slept worse in hospital, and 24 slept better. Of the 28 who slept worse in hospital, only nine stated that this was due to noise.

All 21 nursing staff questioned thought that noise in the ward was sufficient to disturb sleep in about $40 \%$ of patients. Suggested methods of reducing noise included prompt repair of faulty equipment (taps, trolleys, etc), isolation of noisy patients, use of soft soled shoes by staff (particularly medical), muting of noise from patients' alarm systems and telephones, and limitation of conversation between staff within patients' hearing. It was suggested that ear plugs should be provided on request.

\section{Comment}

Because of the logarithmic scale noise levels of $67 \mathrm{~dB}(\mathrm{~A})$ are roughly equivalent to a noise 10 times the recommended level of $35 \mathrm{db}(\mathrm{A})$. The graphic recorder is useful in permitting analysis of both background noise and individual noises.

The minimum level to which noise fell during the night-about 37 $\mathrm{dB}(\mathrm{A})$ - was remarkably constant both between nights and between wards. Air conditioning, present throughout the hospital, produces noise in this range $^{1}$ and is the likely source for this background noise. Patients are unwilling to complain about noise ${ }^{2}$ which may explain the disparity between the results of the questionnaire and the noise recorded.

Suggestions from staff on ways of reducing noise were simple, inexpensive, and practical. By careful planning, teaching, and implementation of constructive criticism the medical, nursing, and engineering professions should be able to make hospitals quieter.

We are grateful to MrI Kelly, Wolfson Unit, Ninewells Hospital, for technical advice and help and to the patients and nursing staff for their help and cooperation.

1 US Environmental Protection Agency. Information on levels of environmental noise requisite to protect public health and welfare with an adequate margin of safety. Washington DC: Environmental Protection Agency, 1974.

2 Whitfield S. Noise on the ward at night. Nursing Times 1975;71:408-12.

(Accepted 30 October 1985)

Ninewells Hospital and Medical School, Dundee

RICHARD L SOUTAR, medical student

JOHN A WILSON, MRCP, senior registrar

Correspondence to: Dr Wilson, Department of Gastroenterology, McMaster University, Hamilton, Ontario, Canada L8N $3 Z 5$.

\section{Employees with epilepsy in the National Health Service}

We carried out a study to determine the number and prevalence of people with epilepsy in the National Health Service.

\section{Methods and results}

We sent a questionnaire to 48 NHS districts in England and Wales asking for the total number of employees in the district, the number known to have epilepsy, the types of job in which people with epilepsy worked, and whether there were any posts for which a history of epilepsy would be a total bar.

We received replies from 45 districts, which had from 1611 to 15447 employees. Sixteen districts did not know how many people with epilepsy they employed, although three employed some as they had noted the kinds of work they carried out. In the 29 other districts the number of people with epilepsy ranged from one to 30 , giving a crude prevalence of $0 \cdot 2-5 \cdot 0 / 1000$ employees (table). Thirty four districts listed the occupations of the people with epilepsy;

Crude prevalences by district of employees in the NHS known to have epilepsy

\begin{tabular}{lccccc}
\hline $\begin{array}{l}\text { Prevalence }(/ 1000) \\
\text { No of districts }\end{array}$ & $<0.5$ & $\begin{array}{c}0.5-0.9 \\
12\end{array}$ & $\begin{array}{c}1 \cdot 0-1 \cdot 4 \\
6\end{array}$ & $\begin{array}{c}1.5-1.9 \\
3\end{array}$ & $\begin{array}{c}\geqslant 2.0 \\
6\end{array}$ \\
\hline
\end{tabular}

many occupations were represented, but, surprisingly, only one doctor with epilepsy was recorded. In 28 districts there were posts from which people with epilepsy were barred. These included jobs that entailed climbing or working at heights and operating machinery. Other restricted posts were in coronary, intensive care, and renal units and as drivers and midwives.

\section{Comment}

The prevalence of active epilepsy in adults is about $3 \cdot 5 / 1000^{1}$; our crude rate of $1 \cdot 35 / 1000$ is lower than that of Dasgupta $e t$ al but about the same as 
that reported by McIntyre in industry. ${ }^{23}$ McIntyre suggested that about one half of cases were undisclosed, and our study supports this. According to Scambler and Hopkins, only one in 10 people with epilepsy always disclosed their disability. ${ }^{4}$ As Gloag pointed out, "people fear... that their job applications will not be considered on their merits if they admit a history of epilepsy and...their medical history will not be assessed by anyone knowledgeable."

How might things be improved? One way is to establish guidelines that distinguish between how prospective new employees with epilepsy and employees who develop epilepsy are dealt with. In the first case the employer should state clearly if particular jobs are unsuitable for people with epilepsy. Espir suggested that people should be rejected on medical grounds only after a medical examination. ${ }^{5}$ In our view this examination should be undertaken by an occupational physician as it is on his advice that the employer relies. Guidelines would be beneficial to all those working in the NHS and ought to ensure a uniform procedure. There are undoubtedly some posts within the NHS that are unsuitable for people with epilepsy, particularly those that entail direct responsibility for the lives or safety of patients or other employees.

If onset of epilepsy occurs after the start of employment a full assessment must be made by the occupational physician in consultation with the employee's medical adviser. Recommendations should be made on the individual merits of each case. Every effort should be made to modify the demands of the post so that it is safe for the employee to continue in it or to find him suitable alternative work. Each employee with epilepsy should be regularly reviewed by the occupational physician so that he can give advice on matters related to work, monitor progress, and allay the anxiety of the employer.

1 Hopkins A. Epilepsy in adults. Medicine International 1983;1:1405-14.

2 Dasgupta AK, Saunders M, Dick DJ. Epilepsy in the British Steel Corporation: an evaluation of sickness, accident, and work records. Br F Ind Med 1982;39:145-8.

4 Scambler G, Hopkins A. Social class, epileptic activity, and disadvantage at work. I Epidemiol Community Health 1980;34:129-33.

5 Gloag D. Epilepsy and employment. BrMed f 1985;291:2-3.

(Accepted 21 November 1985)

London School of Hygiene and Tropical Medicine, London WC1E 7HT

JENNIFER R LISLE, MSC, MFCM, visiting research worker

H A WALDRON, MD, FFOM, senior lecturer in occupational medicine

Correspondence to: Dr Lisle.
3 McIntyre I. Epilepsy and employment. Community Health (Bristol) 1976;7:195.

sharply when the treatment was stopped (figure). Analysis of 10 samples of the human albumin solution administered showed a mean aluminium concentration of $8 \cdot 3 \mu \mathrm{mol} / \mathrm{l}(22 \cdot 4 \mu \mathrm{g} / 100 \mathrm{ml})($ range $7 \cdot 3-9 \cdot 6 \mu \mathrm{mol} / \mathrm{l}(19 \cdot 7-25 \cdot 9 \mu \mathrm{g} / 100 \mathrm{ml}))$.

\section{Comment}

Serum aluminium concentrations in excess of $3.7 \mu \mathrm{mol} / \mathrm{l}(100 \mu \mathrm{g} / \mathrm{l})$ are usually associated with deposition of aluminium in bone, ${ }^{3}$ which may lead to impaired bone formation and mineralisation. In our patient the raised aluminium concentration was clearly related to albumin replacement treatment and not to the usual sources of aluminium loading in patients receiving maintenance haemodialysis. Accumulation of aluminium in renal failure due to albumin replacement treatment has not previously been

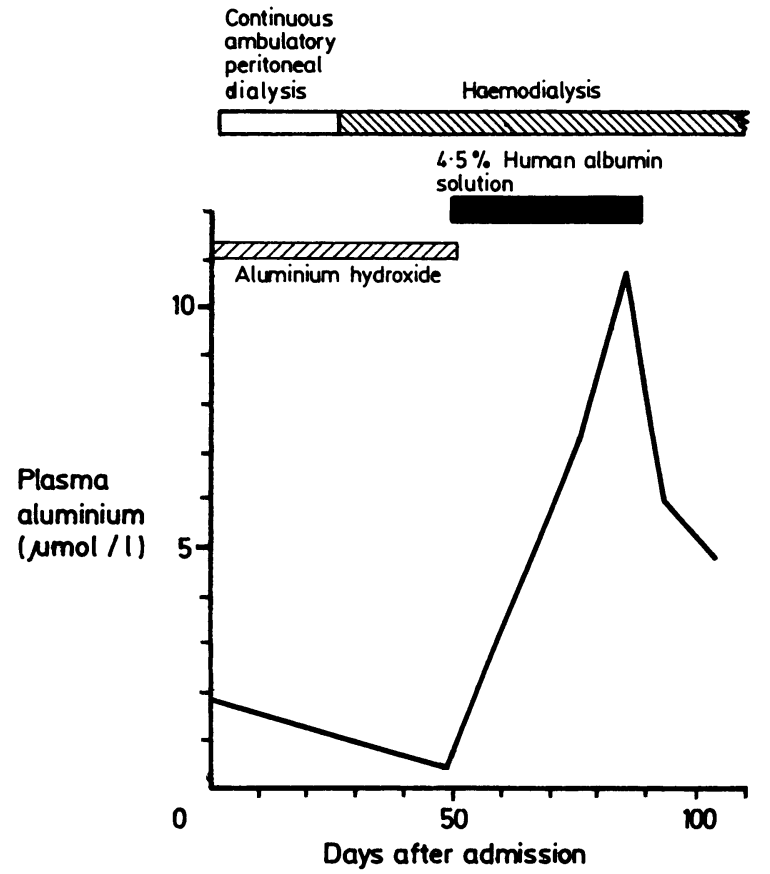

Relation between plasma aluminium concentrations and albumin replacement. Conversion: SI to traditional units_Aluminium: $1 \mu \mathrm{mol} / 1 \approx 2 \cdot 7 \mu \mathrm{g} / 100 \mathrm{ml}$.

described, although a transient increase in plasma aluminium concentration and urinary aluminium excretion after plasmapheresis was reported in a man with a normal serum creatinine concentration. ${ }^{4}$ Other intravenous infusions may contain appreciable amounts of aluminium-for example, parenteral feeding solutions ${ }^{5}$-but this source of aluminium is probably underrecognised.

Aluminium loading due to intravenous treatment is likely to be of particular importance in patients with renal impairment requiring prolonged parenteral nutrition, frequent albumin replacement treatment, or plasmapheresis. osteomalacia resistant to vitamin $D$, dialysis encephalopathy, or microc anaemia. ${ }^{1}$ The usual source of aluminium is the water supply used to prepare the dialysis fluids or aluminium compound ingested as phosphate binders. We report on a patient in whom high plasma aluminium concentrations resulted from another, little recognised source-that is, intravenous infusions of albumin replacement solutions.

\section{Case report}

A 62 year old woman receiving continuous ambulatory peritoneal dialysis for end stage renal failure of uncertain cause was admitted with peritonitis. She failed to respond to standard treatment with intraperitoneal and parenteral antibiotics and on day 25 of her admission was changed to haemodialysis. Thereafter she underwent dialysis for 12 hours each week in two sessions. Aluminium concentrations in the dialysis fluid varied from 0.1 to $0.4 \mu \mathrm{mol} / \mathrm{l}(2 \cdot 7$ to 10.8 $\mu \mathrm{g} / \mathrm{l}$ ). On admission she was taking $2 \cdot 85 \mathrm{~g}$ aluminium hydroxide daily (that is, six Alu-cap capsules daily), and this was continued until day 49 , after which she did not receive any oral aluminium compounds.

Plasma aluminium concentrations (measured by atomic absorption spectrophotometry ${ }^{2}$ ) were low on admission and fell slightly until day 49 (figure). Plasma albumin concentration had fallen to $20 \mathrm{~g} / \mathrm{l}$ on day 49 , and she was given a total of 22 units $(8800 \mathrm{ml})$ of $4.5 \%$ human albumin solution (Blood Products Laboratory, Elstree, Herts) during dialysis from day 48 to day 87 . Coincident with the regular infusion of albumin replacement solutions the plasma aluminium concentrations increased to a potentially toxic value $(10.9 \mu \mathrm{mol} / \mathrm{l}(29 \cdot 4 \mu \mathrm{g} / 100 \mathrm{ml}))$ and then fell

1 Willis MR, Savory J. Aluminium poisoning: dialysis encephalopathy, osteomalacia and anaemia Lancet 1983;ii:29-33.

2 Gardiner PE, Ottoway JM, Fell GS, et al. Determination of aluminium in blood, plasma or serum by electrothermal atomic absorption spectrometry. Analytica Chimica Acta 1981;128:57-66.

3 Charhon SM, Chavassieux PM, Meunier PJ, Accominotti M. Serum aluminium concentration and aluminium deposits in bone in patients receiving haemodialysis. Br Med $\mathcal{F}$ 1985;290:1613-4.

aluminium deposits in bone in patients receiving haemodialysis. Br Med f 1985;290:1613-4.
4 Milliner DS, Shinaberger JH, Shuman RN, Coburn JW. Inadvertent aluminium administration Milliner DS, Shinaberger $\mathrm{JH}$, Shuman $\mathrm{RN}$, Coburn JW. Inadvertent aluminium administration
during plasma exchange due to aluminium contamination of albumin-replacement solutions. $N$

5 Sedman AB, Klein GL, Merritt RJ, et al. Evidence of aluminium loading in infants receiving intravenous therapy. N Engl f Med 1985;312:1337-43.

(Accepted 28 October 1985)

Departments of Medicine and Chemical Pathology, Charing Cross Hospital, London W6 8RF

E R MAHER, BSC, MRCP, research fellow

E A BROWN, DM, MRCP, senior registrar

J R CURTIS, MD, FRCP, senior lecturer in medicine

M E PHILLIPS, MD, MRCP, consultant physician

B SAMPSON, MPHIL, MRSCCCHEM, senior biochemist

Correspondence to: Dr Maher. 